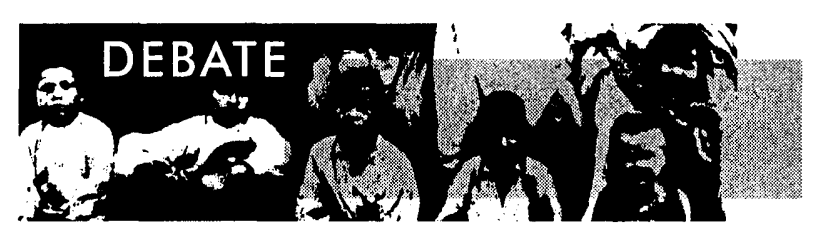

\title{
Conselhos Municipais de Saúde: \\ A Possibilidade dos Usuários Participarem e os Determinantes da Participação
}

\author{
Soraya Maria Vargas Cortes ${ }^{1}$
}

\begin{abstract}
Resumo: $O$ artigo discute afirmações da literatura internacional que atestam as dificuldades em criar canais participatórios nos países em desenvolvimento em geral, e na América Latina em particular, devido à fraqueza de suas instituições políticas e sociedades civis. Na área da saúde, as iniciativas para promover a participação teriam resultado em fracasso. Argumentase, em contrapartida, que a experiência brasileira com os Conselhos Municipais de Saúde não confirma integralmente tais afirmações. $O$ artigo analisa, ainda, os determinantes do sucesso de um processo participatório nesses Conselhos.
\end{abstract}

Palavras-chave: Participação; Conselhos Municipais de Saúde; Determinantes da Participação dos Usuários.

Summary: The paper discusses assessments on difficulties for creating participatory channels in developing countries, particularly in Latin America, due to the weakness of their political institutions as well as civil societies. According to them, in the health field, initiatives to promote participation have been unsuccessful. The paper sustains that the experience of Municipal Health Councils in Brazil does not confirm these affirmations. It also analyses the determinants of a successful participatory process in these Councils.

Keywords: Participation; Municipal Health Councils; Determinants of User Participation.

\footnotetext{
${ }^{1}$ Universidade Federal do Rio Grande do Sul (UFRGS). Instituto de Filosofia e Ciências Humanas (IFCH). Programa de Pós-Graduação em Sociologia (PPGS). Núcleo Interdisciplinar de Pesquisas em Saúde Coletiva (NIPESC).
} 


\section{Introdução}

Este artigo se propõe, inicialmente, a discutir algumas afirmações presentes na literatura internacional sobre a questão da participação no contexto de processos de reforma setorial em países em desenvolvimento, marcadamente no setor saúde. De acordo com os autores, seria muito difícil criar canais participatórios nos chamados países em desenvolvimento, em geral e na América Latina em particular, devido às caraterísticas de suas instituições políticas. Supõe-se que essas estariam dominadas por pactos e acertos informais elitistas e pela fraqueza da sociedade civil (Grindle \& Thomas, 1991). Na área da saúde as iniciativas para promover a participação teriam resultado em manipulação dos participantes, destruição de formas tradicionais de organização política e no recrudescimento da exploração econômica das classes populares (Ugalde, 1985). A experiência brasileira com os Conselhos Municipais de Saúde não confirma integralmente tais afirmações. Estudos revelam que, em alguns casos e em determinadas conjunturas, os Conselhos Municipais de Saúde têm participado do processo decisório no setor e têm contado com a participação de representantes dos usuários de serviços de saúde (Carvalheiro et al., 1992; Cortes, 1995). Daí advém o questionamento sobre as condições que viabilizariam o êxito de tais experiências participatórias. A segunda parte do artigo procura responder à última indagação.

Para que a discussão aqui promovida seja inteligível é necessário fazer dois esclarecimentos iniciais. Em primeiro lugar, a literatura sobre o tema tem tratado como participantes em potencial a comunidade, o consumidor, as classes populares (participação popular), o cidadão e o usuário. A utilização de um ou outro conceito de participante depende principalmente da orientação política e ideológica de quem o empregar. Neste artigo, emprega-se com maior freqüência o conceito de participação dos usuários. Ele se refere àqueles que utilizam determinados serviços em uma dada área territorial. Embora tenha alguma similaridade com o conceito de participação do consumidor, ele não se restringe à perspectiva mercantil e incorpora a noção de direito social que o conceito de cidadania normalmente pressupõe. Além disso, desde a segunda metade da década passada, o termo participação do usuário tem sido o mais empregado pela literatura e pelos documentos oficiais brasileiros. Em segundo lugar, a literatura trabalha com diferentes modalidades ou gradações do que seria participação (Arnstein, 1969; Cortes, 1996a; Ham, 1980; Lee \& Mills, 1985; Paul, 1987). As formas de envolvimento dos participantes podem variar desde a manipulação, consulta ou negociação até a participação. Neste artigo, considera-se que há participação quando o participante toma parte no processo de decisão política (Lee \& Mills, 1985; Paul, 1987). O termo é usado no sentido de "tomar parte em atividades" ou "estar presente", unicamente quando se estiver citando a literatura ou documentos oficiais.

\section{Consolidação de Canais Participa- tórios no Brasil, na Área de Saúde: Improvável mas Possível}

Durante as duas últimas décadas, nos países desenvolvidos, a institucionalização de mecanismos participatórios tem sido vista como um complemento ou como uma alternativa às formas tradicionais de representação política nas democracias liberais. No mesmo período, as agências internacionais têm preconizado que nos países em desenvolvimento seja promovida a auto- 
sustentação econômica e a participação comunitária, vistas como meios para atingir o desenvolvimento. Os cuidados primários de saúde seriam uma das principais estratégias para melhorar as condições de saúde nesses países. Uma de suas diretrizes centrais consiste no estímulo da participação comunitária. Tem sido questionada, no entanto, a possibilidade de serem criados mecanismos que permitam a participação dos setores populares no processo de decisão política em países em desenvolvimento e, particularmente, em países latino-americanos.

Desde os anos trinta, dirigentes políticos e acadêmicos consideravam que o Estado deveria ser o condutor do crescimento econômico e o promotor do bem-estar social (Grindle \& Thomas, 1991:2). Os governos centrais seriam os impulsionadores do progresso, particularmente, nos países em desenvolvimento. Neles, a grande distância entre os objetivos propostos e a realidade, marcada por enormes problemas sociais e econômicos, parecia justificar a defesa do planejamento e execução centralizada. Nos anos oitenta, o agravamento da crise econômica internacional e a ascensão ao poder de políticos conservadores em países centrais da economia internacional determinaram uma mudança de enfoque. Os dirigentes políticos desses países passaram a defender idéias inspiradas no pensamento da nova direita, influenciando as agências internacionais a propor o "ajustamento estrutural" das economias dos países em desenvolvimento através de políticas que reduzissem drasticamente o tamanho do aparelho estatal. As agências internacionais passaram a recomendar reformas baseadas em teorias econômicas neoclássicas, desafiando a idéia do Estado indutor do crescimento econômico e do bem-estar social. Advogava-se uma maior distribuição de poder, na qual a privatização e a devolução de funções e recursos aos níveis sub- nacionais de governo tornaram-se noçõeschaves (Grindle \& Thomas, 1991:2). A nova concepção de desenvolvimento, combinada com a idéia de cuidados primários de saúcle, teve influência profunda na reforma do sistema brasileiro de saúde iniciada nos anos oitenta.

A estratégia de cuidados primários de saúde criticava a concentração de investimentos em poucas unidades complexas de saúde, principalmente hospitais, em geral localizados em alguns centros urbanos de larga densidade populacional (Walt, 1994:5,24). Os recursos deveriam ser usados racionalmente, enfatizando a aplicação de tecnologias simplificadas através de uma rede de serviços hierarquizada que cobriria toda a população, embora tivesse como alvo prioritário os setores sociais mais pobres. Nos países em desenvolvimento, a implantação de políticas inspiradas nessa estratégia freqüentemente resultara ná extensão da cobertura dos serviços de saúde a regiões rurais e a áreas urbanas que concentravam populações de baixa renda (Paim, 1989:19; Walt, 1994:5). A administração da rede de serviços deveria ser descentralizada e contaria com a participação da comunidade.

A noção de participação, tal como fora inicialmente concebida pelos defensores dos cuidados primários de saúde, era muito vaga, e seu significado variava conforme as peculiaridades da organização social e política de cada país, ou do posicionamento político-ideológico do ator político que abraçava a idéia. Segundo Grindle \& Thomas (1991:43-69), nos países em desenvolvimento, os tipos de relações, que normalmente se estabelecem entre instituições políticas $e$ sociedade civil, dificultariam a constituição de mecanismos participatórios. Uma das características desses países seria a fraqueza ou ausência de sociedade civil organizada capaz de contrabalançar o poder político das elites econômicas e militares em 
aliança com a burocracia estatal. Particularmente na América Latina, o processo de tomada de decisões políticas teria sido tradicionalmente conduzido através de canais informais, nos quais os interesses empresariais e militares estariam diretamente representados dentro da estrutura burocrática do Estado (Cardoso, 1975:165-86). Nos países latino-americanos os interesses não dominantes - tais como o dos sindicatos, dos trabalhadores rurais, dos moradores urbanos pobres - seriam sistematicamente excluídos de formas autônomas de representação de interesses. Suas demandas seriam filtradas por relações clientelistas, estabelecidas por políticos e funcionários públicos com líderes obsequiosos e clientes individuais.

Embora essa caracterização seja apropriada para a maior parte da história republicana brasileira, ela é apenas parcialmente adequada para retratar a vida política brasileira durante os anos oitenta. As prescrições das agências internacionais, defendendo a redução do papel do governo federal - como provedor de bens e de serviços - e propondo a participação comunitária, dirigiam-se a um país cuja economia praticamente parara de crescer. Os anos oitenta foram conhecidos como a "década perdida", principalmente, porque se caracterizaram pela combinação de altas taxas de inflação com crescimento econômico negativo ou muito baixo. O declínio da atividade econômica virtualmente neutralizara o governo central como agente indutor do desenvolvimento econômico. No entanto, concomitantemente, a sociedade civil demonstrava uma capacidade de organização sem precedentes, ao mesmo tempo que se liberalizava a vida política.

No final dos anos setenta, intensificava-se a mobilização e a organização da sociedade civil brasileira. O "novo movimento sindical" demandava ativamente aumentos salariais e liberdade de organização enquanto se opunha abertamente à ditadura militar (Almeida, 1984:191-214; Keck, 1989:252-96). Pela primeira vez, desde o começo dos anos sessenta, sindicatos de trabalhadores rurais e o movimento dos sem-terra exigiam reforma agrária e a extensão de benefícios previdenciários a trabalhadores rurais (Grzybowski, 1987; Hall, 1990:187-232). Nas áreas urbanas, associações de moradores promoviam campanhas demandando melhores serviços ou mesmo, por vezes, ocupando conjuntos residenciais vazios e prédios públicos (Baierle, 1992; Martes, 1990). Novas organizações sociais eram criadas, tais como associações ecológicas e grupos feministas. Esses movimentos e organizações tinham como ponto comum a oposição ao governo militar.

O clímax da liberalização política durante os anos oitenta deu-se com o fim da ditadura militar e a promulgação da Constituição em 1988. A Constituição instituiu "um regime competitivo liberal de oligarquias", no qual, todos os brasileiros eram formalmente considerados cidadãos (Weffort, 1988:16). Ela criou mecanismos de envolvimento das classes populares na administração pública - como o referendum, o plebiscito, a iniciativa popular - e estabeleceu formas de participação popular, particularmente na área da saúde (Moisés, 1990:33; Brasil, 1988:art. 194/VII).

A organização da sociedade civil e a liberalização política ocorrida não são sempre incorporadas à análise dos processos recentes de reforma social e das instituições políticas latino-americanas. Grindle e Thomas (1991:63) afirmaram que na maior parte dos países em desenvolvimento, grandes parcelas da população - camponeses e moradores urbanos favelados - não são organizados de modo a sustentar atividades políticas regulares. Os interesses societais seriam freqüentemente representados através de processos informais ao invés de formas públicas de pressão. Esse 
era o caso do Brasil, particularmente durante as décadas de sessenta e setenta, quando se combinavam a ausência de democracia política e a exclusão de milhões de pessoas do acesso a bens e serviços básicos, disponíveis para outros através da rápida industrialização e modernização. Nos anos oitenta e início dos anos noventa, entretanto, essa caracterização torna-se imprecisa, na medida em que retrata apenas parcialmente a dinâmica social $\mathrm{e}$ política do país. Em várias cidades, especialmente na área da saúde, setores dos movimentos sociais urbanos, rurais e sindical mobilizavam-se e, inicialmente, apresentavam suas reivindicações diretamente a gestores e políticos. A partir da segunda metade da década de oitenta, esses movimentos passaram a canalizar suas demandas para as Comissões Interinstitucionais Municipais de Saúde (CIMS), e depois, para os Conselhos Municipais de Saúde. Através desses canais participatórios, eram apresentadas formal e publicamente as demandas daqueles setores sociais recorrentemente excluídos dos processos decisórios. Para que isso ocorresse, de forma sistemática e continuada, seriam necessárias algumas precondições.

Em primeiro lugar, o estabelecimento desses canais de efetiva participação requereria a existência de organizações da sociedade civil, que pudessem sustentar e legitimar aqueles que representassem os interesses dos setores sociais que elas aglutinavam (Marmor, 1983:92). Em segundo lugar, seria necessário contar com uma policy community interessada na construção de canais participatórios. Policy community é entendida como uma comunidade orgânica de atores políticos organizados em torno de um projeto comum de política social (Jordan \& Richardson, 1982:83). Um importante ator dessa comunidade é a elite política setorial, composta por profissionais e acadêmicos que colabo- ram decisivamente para a elaboração de projetos reformistas (Grindle \& Thomas, 1991:20). No caso da reforma do sistema brasileiro de saúde, havia os ativistas dos movimentos sociais, ansiosos por influenciar a formulação e implementação das políticas do setor. Havia, também, uma elite de reformadores tentando criar alianças $e$ coalizões para influenciar o processo de tomada de decisões dentro do governo (Melo, 1993:130-136).

Grindle e Thomas (1991:32-4) relacionaram a fraqueza dos mecanismos de representação de interesses coletivos, nos países em desenvolvimento, ao forte papel que assumiriam as elites políticas setoriais na formulação e na implementação de reformas, independente de articulações com organizações da sociedade civil. No entanto, a elite de reformadores do sistema brasileiro de saúde constituiu-se apenas, em um dos componentes da policy community que defendia a reforma. Por um lado, a elite de reformadores atraiu lideranças populares e sindicais para que esses se envolvessem nos fóruns públicos de representação política que eram criados. Por outro, tomaram parte ativa no desenho de políticas e de estratégias que impulsionassem o processo reformista. Ao invés de tomar decisões através de um processo informal de consulta a uma sociedade civil debilmente organizada, eles promoveram a normalização de mecanismos de representação de interesses coletivos no setor saúde, tendo como pressuposto a existência de movimentos popular e sindical, suficientemente organizados para garantir a continuidade e a consistência desse processo de representação.

$\mathrm{Na}$ década passada, a reforma do sistema brasileiro de saúde tornou os serviços de saúde mais integrados e descentralizados. Ainda não está claro se as mudanças melhoraram a qualidade dos cuidados de saúde oferecidos, se eles se tornaram mais 
acessíveis ou se a reforma ajudou a aprofundar iniqüidades territoriais e sociais que já existiam (Collins, 1989:170). Não há dúvida, no entanto, que desde 1984 foram criados, no nível municipal de governo, fóruns participativos em quase todas as cidades do país, sendo que a maioria deles tem trabalhado regularmente desde a sua criação (IBAM et al., 1993:33). Tanto que, em 1996, 54\% dos municípios do país tinham Conselhos de Saúde (Barros, 1996:12).

Embora, durante os anos oitenta, tenha havido intensa mobilização da sociedade civil no Brasil, a estrutura organizativa daí resultante varia de acordo com a região do país, com o estado e com as características demográficas, econômicas e políticas das cidades. A força de instituições políticas e dos movimentos popular e sindical em cidades grandes, por exemplo, tende a tornar viável a participação de grupos de pressão, determinando o tipo de envolvimento que os usuários teriam nos Conselhos de Saúde (Carvalheiro et al., 1992; Cortes, 1995; IBAM et al., 1991; IBAM et al., 1993; L'Abbate, 1990; Martes, 1990). Clientelismo e paternalismo ainda são características marcantes nas relações entre governo e grupos de interesse no Brasil, especialmente nas pequenas cidades, nas áreas rurais e nas áreas menos industrializadas do país. Embora os Conselhos possam colaborar para a consolidação de formas mais democráticas de representação de interesses, eles têm seu funcionamento limitado e condicionado pela realidade concreta das instituições e da cultura política dos municípios brasileiros. Além disso, mesmo que o fórum participatório se torne a principal arena do processo de decisão política setorial, o setor saúde geralmente não é central na estratégia política dos governos (Walt, 1994:86-8).

Mesmo levando em conta tais restrições, pode estar havendo a formação gradual de um novo tipo de relacionamento na área da saúde no Brasil, no qual os interesses dos setores populares são representados formal e publicamente. Em cidades grandes e em municípios onde os movimentos popular e sindical são mais organizados, tem havido envolvimento constante de seus representantes nos espaços políticos públicos dos Conselhos Locais e Municipais de Saúde (Carvalheiro et al., 1992; Cortes, 1995; Vargas et al., 1985).

Não só as afirmações de Grindle e Thomas sobre a fraqueza da sociedade civil e a informalidade do processo de representação de interesses na América Latina são incompletas, as de Ugalde também o são. Ele (1985:43) afirmou que na América Latina as experiências de participação inspiradas pelos princípios dos cuidados primários de saúde teriam contribuído para aumentar a exploração do pobre através da utilização de seu trabalho gratuito. Elas teriam contribuído para a sua descaracterização cultural, ao mesmo tempo que acentuavam a violência política pela exclusão ou supressão de líderes e a destruição de organizações de base. Os Conselhos de Saúde se constituem em fóruns institucionalizados, similares aos encontrados na Inglaterra, Itália, Estados Unidos ou Canadá (Cortes, 1996b), e não em. "experiências de participação". Uma fonte de inspiração para a criação de seus antecessores - as CIMS foi a proposta de participação comunitária preconizada pelos cuidados primários de saúde. As afirmações de Ugalde podem ser consideradas como parcialmente adequadas para caracterizar experiências participatórias que tiveram lugar, durante as duas últimas décadas, em projetos de extensão de cobertura de cuidados de saúde, no interior do país e em áreas urbanas pobres. Não se aplicam, porém, aos ConseIhos Municipais de Saúde espalhados pelo país.

São inadequadas, portanto, as afirmações de Grindle e Thomas e as de Ugalde, 
que subestimam a possibilidade de participação de setores populares em processos reformistas ou em ações inspiradas pela estratégia de atenção primária à saúde na América Latina e, por conseguinte, no Brasil.

\section{Determinantes da Participação dos Usuários}

Constatou-se, acima que, em alguns casos e em algumas conjunturas, os Conselhos Municipais de Saúde têm sido uma arena dentro da qual os interesses dos setores populares são representados e na qual os representantes desses setores têm participado do processo de tomada de decisão política que lá ocorre. Examina-se agora os determinantes da participação dos representantes dos usuários nestes fóruns. A sistematização da literatura sobre o tema (Cortes, 1995; Jacobi, 1993; Lee \& Mills, 1985; Paul, 1987; Marmor, 1983; Martes, 1990; Vargas et al., 1985) apontou os seguintes fatores como os mais influentes sobre esse processo participatório: (1) mudanças recentes na estrutura institucional do sistema brasileiro de saúde; (2) organização dos movimentos popular e sindical na cidade; (3) relacionamento entre profissionais de saúde pública, marcadamente os que trabalhavam em unidades locais de saúde, e lideranças populares e sindicais; $(4,5,6)$ posições das autoridades federais, estaduais e municipais de saúde em relação à participação; (7) dinâmica de funcionamento do Conselho. Duas observações preliminares devem ser feitas para esclarecer a natureza desses determinantes. Em primeiro lugar, na realidade, todos eles se afetam mutuamente, compondo as partes de um todo integrado e conflituoso. Em segundo lugar, os dois primeiros fatores são os mais decisivos. Ou seja, os fóruns não existiriam não fosse a estrutura institucional que os criou, e somente haverá participação se houver organização da sociedade civil. Em certos casos pode haver resistências das autoridades municipais de saúde em relação à participação dos usuários, e mesmo assim ela pode ocorrer em função da pressão dos movimentos sociais.

As transformações recentes na estrutura institucional do sistema brasileiro de saúde podem ser consideradas como o fator mais influente na determinação do processo participatório que ocorre nos Conselhos Municipais de Saúde. Essas mudanças formam um conjunto de programas, políticas e disposições legais que tiveram e continuam tendo influência decisiva sobre todos os outros fatores relacionados ao processo. Elas se iniciam em 1984, quando foi implementado o programa das Ações Integradas de Saúde, e estendem-se até 1996, com a edição da Norma Operacional do Sistema Único de Saúde (SUS), de novembro de 1996. Esses programas, disposições legais e normas operacionais ofereceram as bases políticas e legais para que o sistema brasileiro de saúde se tornasse: (1) mais integrado, através da unificação do subsetor de saúde pública (Ministério da Saúde, Secretarias Estaduais e Municipais de Saúde) com o subsetor de saúde previdenciária (serviços próprios e contratados do INAMPS); (2) mais descentralizado, repassando funções e transferindo equipamentos e recursos financeiros para as Secretarias Estaduais de Saúde, e mais tarde, para os municípios; e (3) universalizado, formalmente oferecendo cobertura de cuidados de saúde a toda a população brasileira.

Nesse contexto, desde a segunda metade dos anos oitenta, cresceu gradualmente a importância da esfera municipal de governo, ao mesmo tempo que as CIMS e depois Conselhos Municipais de Saúde se disseminaram pelo país. Esses fóruns detinham o poder de estabelecer diretrizes políticas e de planejar e supervisionar o uso dos recursos financeiros transferidos 
do nível federal para a esfera municipal de governo. A municipalização vem colocando sob o controle municipal os equipamentos e os recursos humanos e financeiros necessários para gerir serviços de saúde - próprios e contratados - que estavam anteriormente sob a responsabilidade das Secretarias Estaduais de Saúde e dos Ministérios da Saúde e da Previdência Social. Os Conselhos Municipais de Saúde passaram a ser elementos-chave no contexto da descentralização, na medida em que os governos municipais têm ampliado seu papel no sistema. Realizada a municipalização, coloca-se sob âmbito do município, portanto ao alcance do Conselho, o comando do sistema naquele nível de governo.

No entanto, a força dos movimentos popular e sindical é que determinará a ocorrência ou não de participação de representantes legítimos e autônomos dos setores populares nos Conselhos. Mais que isso, o padrão de organização dos movimentos sociais urbanos influencia o modo como os usuários se envolvem nas atividades do Conselho. Se o padrão de organização for mais centralizado, a tendência é que os representantes dos usuários se envolvam diretamente nas atividades do Conselho Municipal. Se o padrão de organização for mais descentralizado, os representantes usuários chegam ao Conselho Municipal através de organizações locais, tais como os Conselhos Locais de Saúde, Clubes de Mães, Associações Comunitárias ou de Moradores, entre outras (Cortes, 1995). A importância dos movimentos, sociais urbanos, especialmente nas cidades maiores, é decisiva porque os representantes do movimento sindical nos Conselhos - excluídos os que representam trabalhadores de saúde - têm sido minoria. Isso possivelmente se explica pelo fato dos setores de trabalhadores mais mobilizados serem aqueles cujos membros já dispõem de seguros ou planos de saúde especiais, não contan- do unicamente com o SUS para atender a suas necessidades. Em cidades pequenas, onde os sindicatos de trabalhadores rurais são fortes, eles se constituem na principal base de sustentação para a participação continuada de seus representantes junto aos Conselhos Municipais (Vargas et al., 1985). Saliente-se que esses trabalhadores também dispõem apenas do SUS para suprir suas necessidades de atenção à saúde.

Um terceiro fator que tem estimulado o envolvimento de usuários nos Conselhos Municipais de Saúde é a ação combinada dos reformadores do sistema brasileiro de saúde, especialmente os que trabalhavam ao nível local, com a dos ativistas dos movimentos sociais urbanos e sindical (Cortes, 1995; Martes, 1990; Vargas et al., 1985). A elite de reformadores tem atuado também, junto ao executivo e legislativo, visando a introdução de modificações político-institucionais que viabilizem a participação dos usuários. Esses reformadores defendem a participação, porque eles acreditam na democratização do processo de decisão política estatal. Além disso, a aliança com os movimentos sociais oferece suporte político no enfrentamento de resistências dos grupos de interesse contrários às reformas e no confronto dentro do governo com outras áreas políticas, que competem com a de saúde pela obtenção de recursos escassos.

O interesse de setores dos movimentos social ou sindical em reivindicar a melhoria do acesso e da qualidade dos serviços de saúde não se traduz, automaticamente, na canalização de demandas para os Conselhos Locais ou Municipais de Saúde. A elite de reformadores estimulou o envolvimento de lideranças populares e sindicais nos contatos que eles estabeleceram, enquanto profissionais de saúde pública, em unidades ambulatoriais, localizadas em áreas urbanas pobres ou em regiões que concentravam trabalhadores rurais. Eles tam- 
bém favoreceram o envolvimento dos usuários nesses fóruns quando ocupavam cargos como gestores federais, estaduais e municipais de saúde. Em algumas áreas urbanas, como no Setor 4, em Porto Alegre (Cortes, 1995), na Zona Leste de São Paulo (Jacobi, 1993; Martes, 1990), ou em Ronda Alta no Rio Grande do Sul (Vargas, 1985), a já existente intensa mobilização popular em torno das questões de saúde foi canalizada para esses fóruns. Em outras áreas onde também existia a predominância de populações pobres, mas a questão saúde não era tratada como prioridade pelos movimentos sociais locais, o encorajamento dos profissionais de saúde pública foi decisivo para o envolvimento de lideranças populares com as questões de saúde. Sem ele a mobilização para o encaminhamento de soluções para os problemas de saúde teria provavelmente sido menos intensa e a ação política desses segmentos da população não teria convergido necessariamente para os Conselhos de Saúde. A contrapartida para as lideranças dos movimentos sociais urbanos e do movimento sindical era o aumento de sua influência política sobre o processo de tomada de decisões no setor saúde. Através do acesso direto às autoridades de saúde nos Conselhos, eles exerciam pressão pela melhoria da qualidade dos serviços de saúde oferecidos às populações pobres que eles representam. Ao mesmo tempo, eles reforçavam a sua posição de liderança dentro das suas organizações.

Um exemplo do resultado da atuação política dessa policy community de reformadores e lideranças dos movimentos popular e sindical foi o processo de exclusão ou de restrição do número de representantes de entidades médicas e do setor privado nas instâncias decisórias dos Conselhos Municipais (comissões de coordenação, de fiscalização ou plenárias) (ABRASCO, 1995). Em protesto contra essa estratégia de exclusão, e como manifestação contrária à reforma, aquelas entidades vêm se retirando dos Conselhos. No entanto, sua falta de influência sobre o fórum participatório não significa que seu poder sobre o processo de decisão política do setor tenha se restringido. Ao contrário, isso provavelmente significa que eles estejam exercendo sua influência sobre a formulação e implementação de políticas através de canais privilegiados. Nesse caso, mesmo que eles não afetem diretamente o grau de participação dos usuários nesses fóruns, eles estariam influenciando a formação de suas agendas de discussão e contribuindo para limitar o papel decisório desses fóruns dentro do setor saúde.

Um quarto fator que contribui para a participação dos usuários nos Conselhos Municipais de Saúde é a posição das autoridades municipais, estaduais e federais de saúde sobre a participação de usuários. A posição das autoridades municipais pode ser considerada como decisiva, pois muitas veze fórum, e mesmo que não o façam, como gestores municipais, eles influenciam diretamente: (1) na formação da agenda de discussão; (2) no funcionamento geral do fórum; (3) na possibilidade de fazer cumprir as decisões ali tomadas; e (4) na possibilidade de pressionar os gestores estaduais, federais e prestadores de serviços de saúde para o cumprimento dessas decisões. Além disso, na medida em que avançar o processo de descentralização, mais importante se tornará o seu papel no conjunto do sistema, enquanto o das autoridades federais e estaduais declinará.

Um quinto fator determinante da participação é a dinâmica de funcionamento dos Conselhos Municipais de Saúde. Ela está intrinsecamente ligada à forma de coordenação do fórum e à postura do gestor municipal em relação à participação. Ela poderia explicar mudanças de curto prazo 
no envolvimento dos usuários (Cortes, 1995). A sobrecarga de discussões detalhadas sobre despesas a serem realizadas, por exemplo, pode levar ao esvaziamento de reuniões. A divisão clara de competências entre comissões técnicas, jurídicas ou similares pode ajudar a evitar esse tipo de problema, se a intenção for evitá-lo, caso contrário pode se constituir numa estratégia para diminuir o poder deliberativo do Conselho. Da mesma forma, ao limitar as questões que entram na pauta de discussão, o gestor municipal pode fazer com que assuntos importantes para a política de saúde municipal, permaneçam como "nãoquestôes" (Bachrach \& Baratz, 1963). Estando fora da agenda de discussões do Conselho, as decisões relativas a eles serão tomadas em gabinetes, longe, portanto, do escrutínio público.

\section{Considerações Finais}

A partir da Constituição de 1988, alguns setores da administração pública, marcadamente o de saúde, têm sido permeáveis à representação de interesses daqueles setores sociais tradicionalmente alijados do processo político. É certo que essa "novidade" convive com a permanência de arranjos políticos elitistas e de práticas clientelistas e paternalistas que dificultam a generalização dessa nova permeabilidade. A crise econômica dos anos oitenta minou as bases do pacto autoritário que excluía as representações de trabalhadores e de outros setores sociais populares dos centros de decisão política. A liberalização política possibilitou a manifestação pública de uma sociedade civil que demonstrou capacidade de organização autônoma, pelo menos nos principais centros urbanos e nas áreas rurais que concentravam os mais ativos sindicatos de trabalhadores rurais. A consolidação dos Conselhos Municipais de
Saúde, como arena para a qual foram canalizadas as demandas dos movimentos popular e sindical, teve sucesso onde formou-se uma policy community composta por uma elite de reformadores do sistema brasileiro de saúde em aliança com lideranças dos movimentos popular e sindical. Aliança que se solidificou nos Conselhos de Saúde e que tem expressado sua força em fóruns importantes, tais como as Conferências de Saúde. Assim, as afirmações de Grindle e Thomas e as de Ugalde, que consideraram pouco provável a constituição de mecanismos formais e públicos de representação dos interesses das classes populares na América Latina, não retratam integralmente, nem valorizam a novidade que constituem os Conselhos Municipais de Saúde para a vida político-institucional do país.

No entanto, a demora no processo de municipalização dos serviços de saúde, em muitos estados, tem limitado as possibilidades de extensão da agenda de discussões dos Conselhos. Enquanto o gerenciamento dos serviços de saúde nas cidades não estiver sob o controle municipal, o poder de decisão política dos Conselhos, dentro do processo decisório geral do setor, tenderá a ser limitado. Em outras palavras, sem a municipalização, o aumento do controle dos usuários sobre o fórum não significará ampliação do controle sobre a gestão dos serviços de saúde da cidade. Na implementação da municipalização incipiente ou parcial - ou da municipalização plena da atenção básica - como tem sido o caso na esmagadora maioria dos municípios brasileiros, o gestor municipal e, por conseguinte, os Conselhos têm influência limitada sobre o setor saúde. Além disso, o sistema de saúde está dividido em dois subsistemas: o daqueles que dispõem de convênios especiais ou que podem comprar serviços privados diretamente, e o daqueles que somente podem recorrer ao SUS. Isso 
tem levado a que principalmente as populações mais pobres e os portadores de doenças crônicas - em menor proporção se interessem em influir no processo de decisão política sobre serviços de saúde financiados com recursos públicos.

Mesmo considerando tais limitações, tem-se constatado que, em alguns casos e em certas conjunturas, os Conselhos Municipais de Saúde têm propiciado a representação pública dos interesses dos setores populares, e os representantes desses setores têm participado no processo de tomada de decisão política que lá ocorre. Os principais determinantes da participação dos representantes dos usuários nos Conselhos Municipais de Saúde têm sido: (1) mudanças no sistema brasileiro de saúde; (2) características dos movimentos popular e sindical na cidade; (3) relacionamento entre profissionais de saúde pública, marcadamente os que trabalham em unidades locais de saúde, e lideranças populares e sindicais; $(4,5,6)$ posições dos gestores federais, estaduais e, principalmente, municipais em relação à participação; e (7) dinâmica de funcionamento do Conselho. Como foi visto, esses determinantes estão profundamente relacionados e se afetam

\section{Referências bibliográficas}

ABRASCO (1995) - I Congresso Brasileiro de Ciências Sociais em Saúde. Discussão na Comunicação Coordenada "Conselhos de Saúde": In: ABRASCO - A Dimensão da Efetividade. Curitiba, 8 de novembro.

ALMEIDA, M.H.T. (1984) - O Sindicalismo Brasileiro entre a Conservação e a Mudança. In: Sorj, B. \& Almeida, M.H.T. (eds.) - Sociedade e Política no Brasil Pós-64. São Paulo: Brasiliense.

ARNSTEIN, S.R. (1969) - A Ladder of Citizen Participation. Journal of American Institute Planners 35(3):216-24.

BACHRACH, P. \& BARATZ, M.S. (1963) - Decisions mutuamente, embora os dois primeiros possam ser destacados como os mais decisivos.

Não se pode afirmar que a reforma do sistema de saúde brasileiro melhorou a qualidade dos cuidados oferecidos, tornou os serviços mais acessíveis ou se ela, ao contrário, intensificou iniqüidades territoriais e sociais que já existiam. Não há dúvida, no entanto, que ela criou, no nível municipal de governo, um fórum participativo que tem contribuído para a democratização do processo de tomada de decisões no setor saúde. Maior participação de usuários não garante a redução das iniqüidades na promoção de cuidados de saúde para a população. No entanto, a consolidação de fóruns participativos pode auxiliar na democratização das instituições brasileiras, dando VOz a setores sociais tradicionalmente excluídos de representação direta no sistema político. Através deles, seus representantes podem influir na decisão sobre o destino de recursos públicos no setor saúde, podem obter informações, fiscalizar a qualidade dos serviços prestados e podem influenciar a formulação de políticas que favoreçam os setores sociais que eles representam.

and Non-decisions: An Analytical Framework. American Political Science Review 57:632-42.

BAIERLE, S.G. (1992) - Um Novo Princípio Éticopolítico: Prática Social e Sujeito nos Movimentos Populares Urbanos em Porto Alegre nos Anos 80. Dissertação de Mestrado, Universidade Estadual de Campinas, Campinas, mimeo.

BARROS, E. (1995) - Política de Saúde: A Complexa Tarefa de Enxergar Mudanças onde Tudo parece Permanência. Curitiba: I Congresso Brasileiro de Ciências Sociais em Saúde, mimeo.

BRASIL (1988) - Constituição da República Federativa do Brasil. Brasília, 5 de Outubro de 1988. 
CARDOSO, F.H. (1975) - Autoritarismo e Democratização. Rio de Janeiro: Paz e Terra.

CARVALHEIRO, J.R.; DONATO, A.F.; HEIMANN, L.S. et al. (1992) - O Município e a Saúde. São Paulo: Ed. Hucitec.

COLLINS, C.D. (1989) - The Rise and the Fall of the National Centralised Agencies. Public Adminis tration and Development 9(2):168-71.

CORTES, S.M.V. (1995) - User Participation and Reform of the Brazilian Health System: The Case of Porto Alegre. Tese de Doutorado, London School of Economics and Political Science, Department of Social Policy and Administration, Londres, mimeo.

CORTES, S.M.V. (1996a) - Fóruns Participatórios na Área de Saúde: Teorias do Estado, Participantes e Modalidades de Participação. Revista Saúde em Debate 49/50:73-79.

CORTES, S.M.V. (1996b) - As Origens da Idéia de Participação na Área de Saúde. Revista Saúde em Debate 51:30-37.

GRINDLE, M.S. \& THOMAS, J.W. (1991) - Public Choices and Policy Change: The Political Economy of Reform in developing Countries. Londres: The Johns Hopkins University Press.

GRZYBOWSKI, C. (1987). - Caminbos e Descaminbos dos Movimentos Sociais no Campo. Petrópolis: Vozes.

HALL, A.L. (1990) - Developing Amazonia: Deforestation and Social Conflict in Brazil's Carajás Programme. Manchester: Manchester University Press.

HAM, C.J. (1980) - Community Health Council Participation in NHS Planning System. Social Policy and Administration 14(3):221-31.

IBAM (Instituto Brasileiro de Administração Social); MINISTÉRIO DA SAÚDE \& FUNDAÇÃO NACIONAL DE SAÚDE (1991) - Perfil dos Municípios na Área de Saúde. Brasília: IBAM/MS/FNS

IBAM; NESCO/PR (Núcleo de Estudos em Saúde Coletiva); IMS/UERJ (Instituto de Medicina Social); NESCON/UFMG (Núcleo de Pesquisas em Saúde Coletiva e Nutrição); NESS/UFBa (Núcleo de Estudos em Serviços de Saúde); NESC/FIOCRUZ (Núcleo de Estudos em Saúde Coletiva) \& NESCO/UFCE (Núcleo de Estudos em Saúde
Coletiva) (1993) - Avaliação do Funcionamento dos Conselhos Estaduais e Municipais de Saúde: Relatório Executivo. Brasília: MS/Conselho Nacional de Saúde, mimeo.

JACOBI, P. (1993) - Movimentos Sociais e Politicas Públicas. Sào Paulo: Cortez.

JORDAN, G. \& RICHARDSON, J.J. (1982) - The British Policy Style or the Logic of Negotiation? In: Richardson, J.J. (Ed.) - Policy Styles in Western Europe. Londres: Allen \& Unwin.

KECK, M.E. (1989) - The New Unionism in the Brazilian Tradition. In: Stepan, A. (Ed.) Democratising Brazil: Problems of Transition and Consolidation. Oxford: Oxford University Press.

L'ABBATE, S. (1990) - O Direito à Saúde: Da Reivindicação à Realização. Projetos de Política de Saúde em Campinas. Tese de Doutorado, Universidade de São Paulo, São Paulo, mimeo.

LEE, K. \& MILLS, A. (1985) - Policy-making and Planning in the Healtb Sector. Londres: Croom Helm.

MARMOR, T.R. (1983) - Political Analysis and American Medical Care. Nova York: Cambridge University Press.

MARTES, A.C.B. (1990) - A Institucionalização dos Movimentos de Reivindição Urbana: As Secretarias de Saúde e a Participação Popular (19791989). Dissertação de Mestrado, Universidade de São Paulo, São Paulo, mimeo.

MELO, M.A.C. (1993) - Anatomia do Fracasso: Intermediação de Interesses e a Reforma das Políticas Sociais na Nova República. Dados Revista de Ciências Sociais 36(1):119-163.

MOISÉS, J.A. (1990) - Cidadania e Participação: Ensaio sobre o Plebiscito, o Referendo e a Iniciativa Popular na Nova Constituição. São Paulo: Marco Zero.

PAIM, J.N.S. (1989) - As Políticas de Saúde e a Conjuntura Atual. Espaço para a Saúde 1:18-24.

PAUL, S. (1987) - Community Participation in Development Projects: The World Bank Experiences. Washington: The World Bank.

UGALDE, A. (1985) - Ideological Dimensions of Community Participation in Latin America Health Programs. Social Science and Medicine 1:41-53. 
VARGAS, G.P.; SILVA, G.; MORLIM, J.P. et al. (1985) - Participaçào dos Trabalhadores Rurais nos Serviços de Saúde de Ronda Alta. Trabalho de Conclusão de Curso, Escola de Saúde Pública de Porto Alegre, Porto Alegre, mimeo.
WALT, G. (1994) - Health Policy: An Introduction to Process and Power. Londres: Zed Books.

WEFFORT, F.C. (1988) - Notas sobre o Desenvolvimento Político do Brasil. São Paulo: Seminário da UNESP, mimeo. 